\title{
VASCULAR SURGERY AND ENDOVASCULAR THERAPY
}

\section{Focus on Endovascular Technique}

\section{Challenges in Stent Grafting: Dealing with Difficult Neck and Iliac Artery Anatomy}

\author{
FRANK J. CRIADO, M.D., ${ }^{1}$ OMRAN ABUL-KHOUDOUD, M.D., ${ }^{1,2}$ \\ PAUL R. LUCAS, M.D., ${ }^{1}$ and MARCOS F. BARNATAN, M.D. ${ }^{1}$
}

ABSTRACT Development of stent-graft endovascular exclusion has forever changed the management of aortic aneurysms. This new modality is most advantageous for AAA patients who are at high risk for standard open repair. They, in turn, are more likely to present with challenging neck and iliac artery anatomy that may increase the likelihood of failure, and even preclude endoluminal therapy altogether. A complete understanding of critical anatomical issues and available troubleshooting adjunctive techniques is paramount if we are to expand applicability of stent-graft technology to increasing numbers of "difficult" patients with large aneurysms.

Keywords Stent grafting, neck artery anatomy, iliac artery anatomy

Endoluminal stent-graft exclusion is a revolutionary technique that has forever changed management of aortic aneurysmal disease. The procedure tends to be technically demanding; anatomic suitability and related technical difficulties rank among the most pressing issues facing endovascular surgeons today. Such challenges are more likely to be encountered in older, surgically

Perspectives in Vascular Surgery and Endovascular Therapy, Volume 14, Number 2, 2001. Address for correspondence and reprint requests: Frank J. Criado, M.D., Division of Vascular Surgery, Union Memorial Hospital, 3333 North Calvert Street, Suite 570, Baltimore, MD 21218. 'Division of Vascular Surgery, Center for Vascular Intervention, Union Memorial Hospital/MedStar Health, Baltimore, MD, ${ }^{2}$ Health Science Center, VA Medical Center, Memphis, TN. Copyright (C) 2001 by Thieme Medical Publishers, Inc., 333 Seventh Avenue, New York, NY 10001, USA. Tel: +1(212) 584-4662. 1531-0035,p;2001,14,02,041,056,ftx,en;pvs00130x. 